\title{
Pricing and Allotment in a Sea-Cargo Supply Chain with Reference Effect: A Dynamic Game Approach
}

\author{
Lei Xu, ${ }^{1}$ Govindan Kannan, ${ }^{2}$ Xiaoli Yang, ${ }^{1}$ Jian $\mathrm{Li},{ }^{1}$ and Xiukun $\mathrm{Zhao}^{3}$ \\ ${ }^{1}$ School of Management, Tianjin University of Technology, 391 Binshui Xidao, Xiqing District, Tianjin 300384, China \\ ${ }^{2}$ Department of Business and Economics, University of Southern, 5230 Odense, Denmark \\ ${ }^{3}$ School of Business, Nankai University, Tianjin 300071, China
}

Correspondence should be addressed to Xiaoli Yang; yangxiaoli1001@126.com

Received 30 December 2012; Accepted 7 February 2013

Academic Editor: Xiang Li

Copyright (C) 2013 Lei Xu et al. This is an open access article distributed under the Creative Commons Attribution License, which permits unrestricted use, distribution, and reproduction in any medium, provided the original work is properly cited.

\begin{abstract}
The contract between the carrier and forwarder is a long-term issue, and the repeated contract business makes the forwarder develop a reference point based on the contract prices, and this reference effect, to a large extent, affects the forwarder's contract purchasing decisions. Based on that, this paper introduces the reference effect in the sea-cargo supply chain and studies a multipleperiod contract problem between the carrier and the forwarder. It is found that when the capacity price in the spot market is less than the forwarder's willingness-to-pay, the forwarder's contract purchasing decision is not affected by the reference effect, only by the capacity price in the spot market, and the multiple-period contract problem can be simplified into a single-period game. In addition, the carrier's optimal contract wholesale price approaches the capacity price in the spot market. Although, the forwarder's contract purchasing decision depends upon the reference effect, it is difficult to derive the closed-form solution. Moreover, because of the risk in the spot market, the carrier tends to sell his/her capacity in the contract market. Finally, we employ the numerical simulation to study the carrier's contract pricing decisions and the forwarder's capacity purchasing decisions in two cases.
\end{abstract}

\section{Introduction}

In the sea-cargo market, it is commonly seen that the spot market coexists with the contract market $[1,2]$; the specific operational process is as follows. In the first stage, the carrier chooses the advanced-selling strategy to reduce the risk of capacity allotment, that is, to sell most capacity to forwarders or large shippers in advance in order to reduce the demand uncertainty. And then, in the second stage, the remaining space is sold by the carrier to direct-ship shippers on ad hoc or free-sale basis. As to the forwarders, in the first stage the forwarders procure large capacity, which qualifies them for a discount. The discount may depend upon the size of allotment as well as the actual volume tendered by the forwarder [3]. In the second stage, the forwarder drums up downstream shippers; forwarders can offer more services and often better prices to downstream shippers in comparison to the carriers' standard tariff.

The supply chain contracts on capacity allotment focused mostly on their applications in the air transport; for example,
Hellermann [2] studied the application on the real option contract in air transportation, and Gupta [4] analyzed the flexible contract coordination between the carrier and forwarder in air transport. Spinler [1] studied the application of capacity reservation in capital-intensive industry and illustrated the applicability of option reservation in air transport, electronic, and tourism industry. However, because of the differences between air transport and liner transport $[5,6]$, liner transport is different from air transport in many aspects, such as products and services provided, market demand, and operation modes. And the supply chain contract in liner transportation is also different from that in air transport.

In the freight market, due to the long-term and repeated purchase behavior between the forwarder and carrier, the forwarder will develop reference price, through observing carrier's past contract prices or capacity prices in other channels. Comparing current price with the reference price, thereafter, the forwarder makes his capacity procurement decision. Therefore, the reference effect, to a large extent, affects the forwarder's capacity reservation decisions. As to 
the repeated purchasing case, the reference price theory indicates that economic agents are not completely rational, and they always consider the past selling price and make purchasing decisions based on this comparison [7]. To be specific, the forwarder will develop his expectation price or reference price based on the past contract prices and use this expectation price as a reference point to compare with the contract price. If the contract price is higher than the reference price, the forwarder perceives prices as loss and would like to purchase less capacity and turn to other channels to procure; otherwise the forwarder would purchase more on site. In this case, the forwarder's purchasing decisions are based not only on the contract price, but also on the reference price. This reference effect makes the forwarder's purchasing level much different [8].

The liner transport problem we addressed in this paper is consistent with the case where reference effect happens, generally the carrier and forwarder are in a long-term contract trading, and they always develop a long-term cooperation partnership, in each period the carrier determines the contract price, and the forwarder determines his contract purchasing quantity according to the contract price and freight demand. In this way, it makes the forwarder refer to the past contract prices to determine contract purchasing quantity in the long-term contract. And this makes the seacargo market much more complex.

The reminder of this paper is organized as follows. We begin by briefly formulating the problem and provide some notations in Section 2. In Section 3 we develop the mathematical model of the carrier and the forwarder, respectively. Section 4 conducts a numerical study and examines the sensitivity of contract price, spot price, and the demand variance to the carrier's expected profits. In Section 5, we summarize this paper and provide concluding remarks.

\section{Problem Descriptions}

We consider a two-echelon sea-cargo supply chain composed of one single carrier and one single forwarder. Due to the uncertainty of both the demand and price in the freight market, the carrier chooses to sell most capacity to large customers on the contract market, that is, the forwarders and large shippers, in advance. And the reminder capacity is sold on the spot market shortly. The forwarder determines his contract purchasing quantity according to the freight demand and his reference price. In the paper, we adopt the common supply chain contract wholesale contract. In a channel context, we observe in some cases that channel transactions are "governed by simple contracts defined only by a per unit wholesale price" [9]. As noted by Holmström and Milgrom [10], incentive contracts in the real world frequently take simpler forms than what the theory often predicts. This can also happen because firms have little to lose using a simpler contract [11]. We build a Von-Stackelberg model of carrier and forwarder where the carrier is game leader, and the forwarder is game follower. The carrier firstly announces the wholesale price according to the ordering quantity of the forwarder, and the forwarder decides the contract quantity. The mathematical representation of the interaction between carrier and forwarder is based on a stylized model in which certain real-life details have been either omitted or simplified to maintain tractability.

The chronology of events is described as follows. First, the carrier releases her wholesale price contract $\{k(t), q(t)\}$ in each period $t$, where $k(t)$ is the wholesale price per unit capacity. Next, the forwarder determines his contract purchasing quantity $q(t)$ in each period $t$ based on wholesale prices announced by the carrier to achieve his/her long-term revenue maximization.

As described above, this paper studies a finite-period problem; the carrier and forwarder make decisions in multiple periods. Assume that the carrier's cost structure is $\widetilde{c}(W, z)=\widetilde{\beta} W+\widetilde{b} z$, where $\widetilde{\beta}$ is the capacity cost per unit, $\widetilde{b}$ is marginal sale cost per unit, and both $\widetilde{\beta}$ and $\widetilde{b}$ are constant. This assumption has been used widely (such as [12]). Constant variable cost satisfies economic of scale; in this situation, the production cost is the lowest. The two contract marginal costs of sales satisfy $\widetilde{b}^{s} \geq \widetilde{b}^{c}$, that is in accord with the real operation [1].

The demands on the spot market and contract market are independent; this assumption simplifies the revenue management problem $[13,14]$. Moreover, because the difference of market structure and sensitivity of both the carrier and forwarder to the prices of both spot and contract markets, the spot and contract markets are completely separable [2]. In the spot market, it is assumed that the market price is the perfectly competitive equilibrium price $\tilde{p}$, with mean $\mu_{\tilde{p}}$ and standard deviation $\sigma_{\tilde{p}}$, and is the normally distributed with p.d.f. $f(\widetilde{p})$ and c.d.f. $F(\widetilde{p})$. The carrier and forwarder are Price Takers. In the contract market, the forwarder faces a long-term freight demand $Q(p)=a-b p+\varepsilon$, and $a>0, b \geq 0, \varepsilon$ follows the standard normal distribution $\varepsilon \sim N\left(0, \sigma_{\varepsilon}^{2}\right)$ with mean 0 and standard deviation $\sigma_{\varepsilon}$. For linear demand function, $a$ is the largest market demand scale, that is, the downstream customer's capacity demand when the contract price is zero; $b$ means the sensitivity of downstream customer on the contract price; random variable $\varepsilon$ characterizes the uncertainty of the downstream customer's demand on the capacity $[15,16]$. Therefore, the downstream customer's capacity demand follows a normal distribution, with mean $\mu_{\mathrm{Q}}=E[a-b p+\varepsilon]=a-b p$ and standard deviation $\sigma_{\mathrm{Q}}=\sigma_{\varepsilon}$, respectively, and its p.d.f. $g(Q)$ and c.d.f. $G(Q)$.

In the contract and spot market, demand represents the sum of demands from a large number of customers. In the contract market, this is the (limited) number of end customers of the intermediary, in the spot market the (very large) number of spot market buyers. Following the argumentation in Porteus [17, page 613], aggregated demands then are, due to the Central Limit Theorem, approximately normally distributed. Though technically a normal distribution implies a small chance that demand is negative, demands are assumed to be nonnegative, so that $F(x)=0$, as for $x<0$. The probability of negative demand depends on the coefficient of variation $\sigma / \mu$. By keeping $\sigma / \mu$ sufficiently small, the chance of negative demand can be kept negligibly small; for example, for $\sigma / \mu=1 / 3$, the chance of negative demand is $0.135 \%$. 
Lau [18] suggests $\sigma / \mu<0.3$ to keep the negative tail negligible. For the model at hand, let $\mu>3 \sigma, i=\widetilde{p}, Q$. The assumption of normally distributed demand is widely used in supply contract (cf. [19]) and revenue management models (cf. [20]).

\section{Model}

3.1. The Forwarder's Decision Problem. The forwarder has a willingness-to-pay $U$ and its form is $U=U(q(k))$, where $U$ is a concave and strictly increasing function of $q(k)$, that is, $U_{1}>0, U_{11} \leq 0$, and $k$ is the wholesale price in the contract market. According to the reference effect theory, the reference price is the expected price which economic agents make according to their own estimation on the capacity prices. The forwarder's willingness-to-pay is the expectation price plus a certain level of profit $p=r+\lambda$. According to the adaptation prospect theory framework of Nerlove [21], the reference price equation is $r_{t}=\alpha r_{t-1}+(1-\alpha) k_{t-1}$, and $\alpha \in[0,1)$. The index smooth application form is most widely used, and the reference price form has empirically tested [2224]. This paper adopts the cost-plus way between the carrier and forwarder based on Hellermann [2]; cost-plus ratio $\lambda$ is constant. Thus the forwarder's willingness-to-pay is $r+\lambda$.

Without considering the discount factor, the forwarder makes decision by maximizing his expected utility in riskneutral condition. Then the forwarder's utility function is given as a newsboy revenue function:

$$
\begin{aligned}
V(q, k, \tilde{p})= & U(q)-k q+U\left((Q-q)_{\tilde{p}<U_{1}}^{+}\right) \\
& -\tilde{p}(Q-q)_{\tilde{p}<U_{1}}^{+} .
\end{aligned}
$$

When $\tilde{p} \geq U_{1}$, the forwarder's capacity purchasing quantity is zero in the spot market. Meanwhile, without loss of generality, we assume that residual value of the unsold capacity is zero at the flight departure time.

Since $U_{1}=(r+\lambda)$, the forwarder's expected utility function can be rewritten into

$$
\begin{aligned}
& V(q) \\
& =\left\{(r+\lambda)\left[\min \{q, Q\}+(Q-q)^{+}\right]-k q-\tilde{p}(Q-q)^{+}\right\}_{\tilde{p}<U_{1}} \\
& \quad+\{(r+\lambda) \min \{q, Q\}-k q\}_{\tilde{p} \geq U_{1}} .
\end{aligned}
$$

According to the capacity contract provided by the carrier, the forwarder's optimal reservation quantity can be obtained by solving the following problem:

$$
\begin{array}{ll}
\max _{q} & V(q) \\
\text { s.t. } & q \geq 0 .
\end{array}
$$

Theorem 1. The forwarder's expected utility function $V(q$, $k, \widetilde{p})$ is a concave function of contract purchasing quantity $q$.
Proof. According to the characteristic of the concave function, the sum of two concave functions is still a concave function. Thus formula (2) can be rewritten into

$$
V(q)=\left\{\begin{array}{c}
\{(r+\lambda) \min \{q, Q\}-k q\}, \\
\tilde{p} \geq r+\lambda, \\
\left\{(r+\lambda)\left[\min \{q, Q\}+(Q-q)^{+}\right]\right. \\
\left.-k q-\widetilde{p}(Q-q)^{+}\right\}, \\
\widetilde{p}<r+\lambda .
\end{array}\right.
$$

The forwarder's expected utility function can be further divided into

$$
E[V(q)]=\left\{\begin{array}{c}
(r+\lambda) E[Q]-k q \\
-(r+\lambda) \int_{q}^{\infty}(Q-q) g(Q) d Q, \\
\widetilde{p} \geq r+\lambda, \\
(r+\lambda) E[Q]-k q \\
-\widetilde{p} \int_{q}^{\infty}(Q-q) g(Q) d Q, \\
\tilde{p}<r+\lambda,
\end{array}\right.
$$

where in the above two cases, the first term is the forwarder's average profit, the second term indicates the capacity purchasing cost, and the last term is expected loss for capacity shortage.

From the newsboy model, the formula (2) is a basic newsboy model, and it is a concave function of $q$. The first term $(r+\lambda) E[Q]$ is constant and is also a concave function of $q$.

Therefore, we only need to prove that term

$$
\Delta(q)= \begin{cases}-k q-(r+\lambda) \int_{q}^{\infty}(Q-q) g(Q) d Q, & \tilde{p} \geq r+\lambda, \\ -k q-\tilde{p} \int_{q}^{\infty}(Q-q) g(Q) d Q, & \tilde{p}<r+\lambda\end{cases}
$$

is a concave function of $q$, to prove $E[V(q)]$ has the optimal purchasing quantity $q^{*}$. Proving that $E[V(q)]$ is a concave function of $q$ can be obtained by proving that $\Delta(q)$ is a concave function of $q$. Taking the first-order derivative $\Delta(q)$ with respect to $q$, we can obtain that

$$
\frac{\partial \Delta(q)}{\partial q}= \begin{cases}-k-(r+\lambda)[G(q)-1], & \tilde{p} \geq r+\lambda, \\ -k-\tilde{p}[G(q)-1], & \tilde{p}<r+\lambda .\end{cases}
$$

By taking the second-order derivative, we can derive that

$$
\frac{\partial^{2} \Delta(q)}{\partial q^{2}}= \begin{cases}-(r+\lambda) g(q)<0, & \tilde{p} \geq r+\lambda \\ -\tilde{p} g(q)<0, & \tilde{p}<r+\lambda\end{cases}
$$

Therefore, $\Delta(q)$ is a concave function of $q$; this means that $E[V(q)]$ is a concave function of $q$.

Theorem 1 indicates that there exists the optimal contract purchasing quantity for the forwarder to maximize his expected utility. Then we derive the forwarder's contract purchasing quantity in the following Theorem. 
Theorem 2. The forwarder's optimal contract purchasing quantity satisfies that

$$
q^{*}=\arg \max E[V(q)] .
$$

Proof. According to the result of Theorem 1, the forwarder can determine his optimal contract purchasing quantity $q^{*}$ to maximize his expected utility.

Equation $E[V(q)]$ can be rewritten as

$$
E[V(q)]=\left\{\begin{array}{c}
(r+\lambda) E[Q]-k q \\
-(r+\lambda) \int_{q}^{\infty}(Q-q) g(Q) d Q, \\
\tilde{p} \geq r+\lambda, \\
(r+\lambda) E[Q] \\
-k q-\tilde{p} \int_{q}^{\infty}(Q-q) g(Q) d Q, \\
\tilde{p}<r+\lambda .
\end{array}\right.
$$

By taking the first-order derivative of $E[V(q, k, \widetilde{p})]$ with respect to $q$, we can obtain that

$$
\frac{\partial \Delta(q)}{\partial q}= \begin{cases}-k-(r+\lambda)[G(q)-1], & \tilde{p} \geq r+\lambda, \\ -k-\tilde{p}[G(q)-1], & \widetilde{p}<r+\lambda .\end{cases}
$$

When $\partial \Delta(q) / \partial q$ is equal to zero, we can obtain that

$$
G\left(q^{*}\right)= \begin{cases}\frac{r+\lambda-k}{r+\lambda}, & \tilde{p} \geq r+\lambda, \\ \frac{\tilde{p}-k}{\tilde{p}}, & \tilde{p}<r+\lambda .\end{cases}
$$

Thus we can derive the forwarder's optimal contract purchasing quantity as follows:

$$
q^{*}= \begin{cases}G^{-1}\left[\frac{r+\lambda-k}{r+\lambda}\right], & \tilde{p} \geq r+\lambda, \\ G^{-1}\left[\frac{\tilde{p}-k}{\tilde{p}}\right], & \tilde{p}<r+\lambda .\end{cases}
$$

Theorem 2 is similar to the result of standard newsboy model, in the two cases: the shortage cost is $\widetilde{p}-k(\widetilde{p}<r+\lambda)$ and $r+\lambda-k(\tilde{p} \geq r+\lambda)$, both overage costs are $k$. $\tilde{p}$ is the forwarder's capacity purchasing cost in the spot market. If purchasing capacity in the contract market cannot meet the downstream customer's demand, when $\widetilde{p} \geq r+\lambda$, the capacity shortage cost is $r+\lambda-k$; when $\tilde{p}<r+\lambda$, the capacity shortage cost is $\widetilde{p}-k$ and is equal to the expected spot market premium. This shows that in the absence of the spot market, because the forwarder cannot procure capacity from the spot market once the downstream customer's demand is realized, this results in an opportunity loss; therefore the forwarder's shortage cost is higher than that when the spot market exists; then we have that $r+\lambda-k>\widetilde{p}-k$. If the forwarder's contract purchasing quantity is more than the downstream customer's demand, because no secondary market considered, the overage cost is $k$ per unit.
Corollary 3. The carrier's contract wholesale price $k$ must satisfy the following condition:

$$
\widetilde{\beta} \leq k \leq \min \{\tilde{p}, r+\lambda\} .
$$

Proof. By the assumptions, we have that $k$ must satisfy that $k \leq r+\lambda$; only this condition holds; the forwarder choose to purchase the capacity in the contract market.

According to the result of Theorem 2 , we have $0 \leq(\widetilde{p}-$ $k) / \widetilde{p} \leq 1$, so $0<k \leq \tilde{p}$.

Moreover, because the fixed cost per unit capacity is $\widetilde{\beta}$, then the wholesale price satisfies $k \geq \widetilde{\beta}$. In sum, we can obtain that $\widetilde{\beta} \leq k \leq \min \{\tilde{p}, r+\lambda\}$.

By the result of Corollary 3 , the conditions $r+\lambda>k(\widetilde{p} \geq$ $r+\lambda)$ and $\tilde{p}>k(\widetilde{p}<r+\lambda)$ are participation constraint for the forwarder to accept capacity contract. Only when $\tilde{p} \geq$ $r+\lambda$, the forwarder's willingness-to-pay is greater than the out-of-pocket cost, that is, $\widetilde{p} \geq r+\lambda$; or when $\widetilde{p}<r+\lambda$, the capacity price in the spot market $\tilde{p}$ is greater than the contract wholesale price, that is, $\widetilde{p}>k$.

By the result of Theorem 2, when determining contract wholesale price, the carrier needs to consider not only the forwarder's willingness-to-pay, but also the spot market price $\tilde{p}$. When $\widetilde{p}<r+\lambda$, the forwarder purchases capacity in both the contract market and the spot market simultaneously. Otherwise, when $\widetilde{p} \geq r+\lambda$, it is a classical newsboy model; the spot market is "nonexistent"; the forwarder does not consider the impact of spot market prices.

Because of the substitution between the contract market and spot market, the capacity price in the spot market will affect the carrier's pricing of the capacity contract and contract the forwarder's capacity purchasing decision. To be specific, the bigger the spot price $\widetilde{p}$ is, the bigger $1-k / \widetilde{p}$ is; then the carrier can make a higher contract wholesale price and vice versa. This is also consistent with the reality case. And the bigger the spot price is, the more the forwarder will purchase capacity in the contract market by the crossprice elasticity $\varepsilon_{q^{*}, \tilde{p}}=\left(\partial q^{*} / \partial \tilde{p}\right) \times\left(\tilde{p} / q^{*}\right)$. By the result of Theorem 2, the bigger the spot price $\tilde{p}$ is, the more the forwarder purchases contract $q^{*}$. When $\widetilde{p} \geq r+\lambda$, it is the classical newsboy model; in this case, the carrier only needs to consider the demand uncertainty.

Meanwhile, Theorem 2 shows that when $\widetilde{p}<r+\lambda$, $1-k /(r+\lambda)>1-k / \tilde{p}$, that is, $\Phi^{-1}[1-k /(r+\lambda)]>$ $\Phi^{-1}[1-k / \tilde{p}]$. The spot market makes the forwarder have more purchasing options; this results in a less contract capacity; the forwarder purchases more than when there is no spot market. To be specific, the forwarders can consider the spot market as an auxiliary capacity source when purchasing capacity from the contract market; when the contract purchasing quantity is less than the downstream customer's demand, the forwarder can turn to the spot market to procure more capacity and compare the spot price with his willingnessto-pay. Theoretically, the forwarder's contract purchasing quantity should fall in a range, that is, $q^{*} \leq E\left[q^{*}\right] \leq \bar{q}^{*}$, where $E\left[q^{*}\right]=\int_{0}^{r+\lambda} \underline{q}^{*} f(\tilde{p}) d \tilde{p}+\int_{r+\lambda}^{\infty} \bar{q}^{*} f(\tilde{p}) d \widetilde{p}$ and $\bar{q}^{*}=$ $\mu_{\mathrm{Q}}+\sigma_{\mathrm{Q}} \Phi^{-1}[1-k /(r+\lambda)], q^{*}=\mu_{\mathrm{Q}}+\sigma_{\mathrm{Q}} \Phi^{-1}[1-k / p]$. 
In order to solve the optimal purchasing quantity $q^{*}$, define $z_{q}=\left(q^{*}-\mu_{\mathrm{Q}}\right) / \sigma_{\mathrm{Q}} \cdot \varphi(\cdot)$ and $\Phi(\cdot)$ denoting the probability density function and the cumulative distribution function of the standard normal distribution. Therefore, we have

$$
\begin{gathered}
q^{*}=\mu_{\mathrm{Q}}+z_{q} \sigma_{\mathrm{Q}}, \\
z_{q}= \begin{cases}\Phi^{-1}\left[1-\frac{k}{r+\lambda}\right], & \tilde{p} \geq r+\lambda, \\
\Phi^{-1}\left[1-\frac{k}{\tilde{p}}\right], & \tilde{p}<r+\lambda .\end{cases}
\end{gathered}
$$

Corollary 4. When $\widetilde{p} \geq r+\lambda$, the contract purchasing quantity $q^{*}$ is an increasing function of the reference price $r$, and the wholesale price $k_{t-1}$ in the previous period is a decreasing function of the current price $k_{t}$; when $\widetilde{p}<r+\lambda$, $q^{*}$ is an increasing function of the spot price $\tilde{p}$ and is a decreasing function of the current price $k_{t}$.

Proof. Solving the first-order derivative of (15), we obtain the following.

When $\widetilde{p} \geq r+\lambda$, we have

$$
\begin{aligned}
\frac{\partial q^{*}}{\partial r} & =\frac{\partial\left(\mu_{\mathrm{Q}}+z_{q} \sigma_{\mathrm{Q}}\right)}{\partial r} \\
& =b+\Phi^{-1^{\prime}}\left[1-\frac{k}{r+\lambda}\right] \cdot \frac{k}{(r+\lambda)^{2}}>0, \\
\frac{\partial q^{*}}{\partial k}= & \frac{\partial\left(\mu_{\mathrm{Q}}+z_{q} \sigma_{\mathrm{Q}}\right)}{\partial k} \\
= & \Phi^{-1^{\prime}}\left[1-\frac{k}{r+\lambda}\right] \cdot\left(-\frac{1}{(r+\lambda)}\right)<0, \\
\frac{\partial q^{*}}{\partial k_{t-1}}= & \frac{\partial\left(\mu_{\mathrm{Q}}+z_{q} \sigma_{\mathrm{Q}}\right)}{\partial k_{t-1}} \\
= & \Phi^{-1^{\prime}}\left[1-\frac{k}{\alpha r+(1-\alpha) k_{t-1}+\lambda}\right] \\
& \cdot \frac{(1-\alpha) k}{\left[\alpha r+(1-\alpha) k_{t-1}+\lambda\right]^{2}}>0 .
\end{aligned}
$$

When $\widetilde{p}<r+\lambda$, we have

$$
\begin{gathered}
\frac{\partial q^{*}}{\partial k}=\frac{\partial\left(\mu_{\mathrm{Q}}+z_{q} \sigma_{\mathrm{Q}}\right)}{\partial k}=-\left[b+\frac{1}{\widetilde{p}} \Phi^{-1^{\prime}}\left[1-\frac{k}{\widetilde{p}}\right]\right]<0, \\
\frac{\partial q^{*}}{\partial \widetilde{p}}=\frac{\partial\left(\mu_{\mathrm{Q}}+z_{q} \sigma_{\mathrm{Q}}\right)}{\partial \widetilde{p}}=\frac{k}{\widetilde{p}^{2}} \Phi^{-1^{\prime}}\left[1-\frac{k}{\widetilde{p}}\right]>0 .
\end{gathered}
$$

Thus this Corollary is derived.

Corollary 4 shows that when $\widetilde{p}<r+\lambda$, the forwarder does not consider contract price in the previous period; this means that the forwarder's decisions are not affected by the reference effect, and it is only related to the wholesale price in the current period.
3.2. The Carrier's Decision Problem. The carrier sells her most capacity to the large customers, that is, forwarders and other large shippers, in advance with the form of capacity contract. In the second phase, the remainder capacity is sold in the spot market by the spot price. In the spot market, the carrier faces the risk of price uncertainty and capacity incompletely sold. In this case, advanced-selling strategy can hedge the risk from demand and price in the spot market, which is the main reason why the carrier chooses to sell the capacity in advance $[1,25]$. Here we assume that the risk factor in the spot market is $\widetilde{m}$, and $0 \leq \widetilde{m} \leq 1$.

Moreover, the contract relationship between the carrier and forwarder is long term. Tsay [19] distinguished three effects of supply chain contract, where the supply chain contract coordination can help to form a long-term stable and cooperative partnership between businesses participates. Besides sharing the market risks, the contract coordination in practice between the carrier and forwarder focuses on the maintenance of long-term cooperative relationship. The carrier and forwarder will maintain such relationship through certain strategy in order to maximize the total profit of the supply chain [26].

First, we give the carrier's single-period decision-making problem and analyze the impact of the decision variables and state variables on the carrier expected profit function. One has

$$
\begin{array}{r}
\Pi(k)=\left(k-\widetilde{b}^{c}\right) q^{*}+\widetilde{m}\left(W-q^{*}\right)\left(\tilde{p}-\widetilde{b}^{s}\right)^{+}-\widetilde{\beta} W \\
\text { s.t. } 0 \leq k \leq \min \{\tilde{p}, r+\lambda\},
\end{array}
$$

where the first term accounts for the profit generated through the long-term contract, the second term represents the profit derived from the spot market with a risk factor $\widetilde{m}$, and the last term displays the cost of holding capacity $W$.

Due to the impact of the forwarder's contract purchasing quantity, we consider two cases about the carrier's the singleperiod decision-making problem, that is, $E[\tilde{p}] \geq r+\lambda$ and $E[\tilde{p}]<r+\lambda$.

3.2.1. Two Cases on Spot Market Prices. Because of the price uncertainty in the spot market, the forwarder's contract purchasing quantity is different. When $\widetilde{p} \geq r+\lambda$, the capacity price in the spot market is higher than the forwarder's willingness-to-pay. Thus the forwarder procures capacity completely in the contract market. When $\widetilde{p}<r+\lambda$, the forwarder procures capacity in both markets, contract market and spot market, and capacity purchasing quantities are $q^{*}$ and $E[Q]-q^{*}$, respectively.

Case $1(\widetilde{p}<r+\lambda)$. According to Corollary 4 in Section 3.1, when $\tilde{p}<r+\lambda$, the forwarder's contract purchasing quantity is unrelated to his reference price. Therefore, when $\widetilde{p}<$ $r+\lambda$, the game problem between the carrier and forwarder becomes a single-period game problem. 

follows:

Therefore, the carrier's decision problem is given as

$$
\begin{array}{r}
\Pi(k)=\left(k-\widetilde{b}^{c}\right) q^{*}+\widetilde{m}\left(W-q^{*}\right)\left(\tilde{p}-\tilde{b}^{s}\right)^{+}-\tilde{\beta} W, \\
\text { s.t. } \quad q^{*}=\mu_{\mathrm{Q}}+z_{q} \sigma_{\mathrm{Q}}, \quad z_{q}=\Phi^{-1}\left[1-\frac{k}{\widetilde{p}}\right], \quad \widetilde{p}<r+\lambda .
\end{array}
$$

Theorem 5. When $\tilde{p}<r+\lambda$, the carrier's optimal contract wholesale price satisfies

$$
k^{*}=E[\tilde{p}] .
$$

Proof. Integrating (19),

$$
\Pi(k)=\left[k-\widetilde{b}^{c}-\widetilde{m}\left(\widetilde{p}-\widetilde{b}^{s}\right)^{+}\right] q^{*}+\left[\widetilde{m}\left(\widetilde{p}-\widetilde{b}^{s}\right)^{+}-\widetilde{\beta}\right] W .
$$

By taking the first-order derivative, we have

$$
\begin{aligned}
& \frac{\partial \Pi(k)}{\partial k} \\
& =\frac{\partial\left[k-\widetilde{b}^{c}-\widetilde{m}\left(\tilde{p}-\tilde{b}^{s}\right)^{+}\right] q^{*}}{\partial k} \\
& =\frac{\partial\left[k-\widetilde{b}^{c}-\widetilde{m}\left(\widetilde{p}-\widetilde{b}^{s}\right)^{+}\right]\left[\mu_{\mathrm{Q}}+z_{q} \sigma_{\mathrm{Q}}\right]}{\partial k} \\
& =\left(\mu_{\mathrm{Q}}+z_{q} \sigma_{\mathrm{Q}}\right)+\left[k-\widetilde{b}^{c}-\widetilde{m}\left(\widetilde{p}-\widetilde{b}^{s}\right)^{+}\right] \sigma_{\mathrm{Q}} \frac{\partial z_{q}}{\partial k} \\
& \frac{\partial z_{q}}{\partial k}=-\frac{1}{\widetilde{p}} \Phi^{-1^{\prime}}\left[1-\frac{k}{\widetilde{p}}\right] .
\end{aligned}
$$

Thus $\partial \Pi(k) / \partial k=\left(\mu_{\mathrm{Q}}+z_{q} \sigma_{\mathrm{Q}}\right)-\left(\sigma_{\mathrm{Q}} / \widetilde{p}\right) \Phi^{-1^{\prime}}[1-k / \widetilde{p}][k-$ $\left.\tilde{b}^{c}-\widetilde{m}\left(\tilde{p}-\tilde{b}^{s}\right)^{+}\right]$. The term $k^{*}-\tilde{b}^{c}$ is the marginal profit from the contract market; the term $\widetilde{m}\left(\widetilde{p}-\widetilde{b}^{s}\right)^{+}$is the marginal profit from the spot market. The necessary condition that the carrier chooses to sell capacity in the contract market is that the marginal profit from the contract market is not less than that from the spot market, that is, $k^{*}-\widetilde{b}^{c} \geq \widetilde{m}\left(\widetilde{p}-\widetilde{b}^{s}\right)^{+}$.

By the result of Corollary 4 , we have $\partial q^{*} / \partial k<0$.

Thus, $\left(\mu_{\mathrm{Q}}+z_{q} \sigma_{\mathrm{Q}}\right)-\left(\sigma_{\mathrm{Q}} / \tilde{p}\right) \Phi^{-1^{\prime}}[1-k / \tilde{p}]\left[k-\widetilde{b}^{c}-\widetilde{m}(\tilde{p}-\right.$ $\left.\left.\tilde{b}^{s}\right)^{+}\right]<0$.

When $q^{*}>\left(\sigma_{\mathrm{Q}} / \tilde{p}\right) \Phi^{-1^{\prime}}\left[1-k^{*} / \tilde{p}\right]\left[k-\widetilde{b}^{c}-\widetilde{m}\left(\widetilde{p}-\widetilde{b}^{s}\right)^{+}\right]>$ $0, \Pi(k)$ is monotonically increasing in $k$, and the carrier's optimal contract wholesale price is $k^{*}=E[\tilde{p}]$.

This theorem shows that when $\widetilde{p}<r+\lambda$, the reference effect does not affect the carrier's decisions, and her multipleperiod decision problem can be considered as a single-period decision problem. And this Theorem also implies that the carrier's optimal wholesale price is the expectation of the capacity price in the spot market.
Theorem 6. The carrier's profit function $\Pi(k)$ is increasing with respect to the wholesale price $k$.

This theorem can be easily derived from Theorem 5 .

Case $2(\tilde{p} \geq r+\lambda)$. Because of the price volatility in the spot market, there is no clear relationship between the forwarder's willingness-to-pay and spot price, and it is always crosssectional linked. Without loss of generality, we take the twoperiod decision-making problem as an example to analyze the carrier's decisions; in the first period, the carrier determines the contract wholesale price according to the forwarder's initial reference price, and the contract parameters will affect the decisions in the subsequent period. Therefore, the carrier's decision is to maximize his two-period profit. It is worth noting that this problem can straightforwardly extended to the multiple-period problem.

Assuming that the carrier is a risk-neutral economic agent, the carrier decision is a two-period profit function.

First, the carrier's single-period decision problem is given as follows:

$$
\begin{array}{r}
\Pi(k)=\left(k-\widetilde{b}^{c}\right) q^{*}+\widetilde{m}\left(W-q^{*}\right)\left(\tilde{p}-\widetilde{b}^{s}\right)^{+}-\tilde{\beta} W \\
\text { s.t. } \quad q^{*}=\mu_{\mathrm{Q}}+z_{q} \sigma_{\mathrm{Q}}, \quad z_{q}=\Phi^{-1}\left[1-\frac{k}{r+\lambda}\right], \\
\widetilde{p} \geq r+\lambda .
\end{array}
$$

We can obtain the carrier's optimal wholesale price in the following Theorem.

Theorem 7. When $\tilde{p} \geq r+\lambda$, the carrier's optimal wholesale price satisfies

$$
k^{*}=r+\lambda
$$

The proof is similar to Theorem 5 (proof is abbreviated).

Theorem 8. When $\tilde{p} \geq r+\lambda$, the carrier's profit function is increasing with respect to wholesale price $k$.

This Theorem can be derived straightforwardly from Theorem 7.

\section{Numerical Analysis}

The above sections have analyzed the dynamic game between the carrier and forwarder. In this section, we mainly focus on examining the impact of the parameters on the carrier's and forwarder's decisions. The variables and parameters throughout this paper are given in Table 1.

4.1. The Forwarder's Optimal Reservation Strategy. Figures 1 and 2 show that when the capacity price in the spot market is low enough, even if the wholesale price in the contract market is low enough, the forwarder still will choose to procure capacity in the spot market. This is because the inflexibility of the contract prevents the forwarder's capacity purchasing option in the spot market; therefore the rational 
TABLE 1: Simulation parameters.

\begin{tabular}{|c|c|c|}
\hline Variable & Value & Variable description \\
\hline$W$ & 400 & The carrier's total capacity \\
\hline$r_{0}$ & $25 \backslash 35$ & The forwarder's initial reference price \\
\hline$\mu_{\mathrm{Q}}$ & 200 & The mean of downstream customer's demand \\
\hline$\sigma_{\mathrm{Q}}$ & 20 & $\begin{array}{l}\text { The standard deviation of downstream } \\
\text { customer's demand }\end{array}$ \\
\hline$\tilde{b}^{c}$ & 8 & The operation cost in the contract market \\
\hline$\tilde{b}^{s}$ & 10 & The operation cost in the spot market \\
\hline$\mu_{\tilde{p}}$ & 40 & The mean of capacity price in the spot market \\
\hline$\sigma_{\tilde{p}}$ & 5 & $\begin{array}{l}\text { The standard deviation of capacity price in the } \\
\text { spot market }\end{array}$ \\
\hline$\widetilde{m}$ & 0.8 & The risk factor in the spot market \\
\hline$\lambda$ & 10 & The forwarder's cost-plus ratio \\
\hline$\alpha$ & 0.4 & The forwarder's memory effect \\
\hline$\tilde{\beta}$ & 5 & The carrier capacity holding cost \\
\hline
\end{tabular}

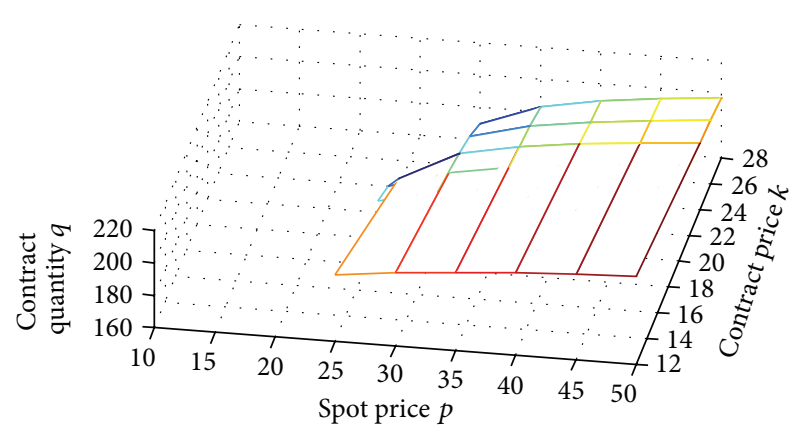

FIGURE 1: The relationship among the contract purchasing quantity, spot price, and contract price (observation chart in azimuth $10^{\circ}$ and angle $65^{\circ}$ ).

forwarder will choose to procure few enough capacity in the contract market, even abandon the contract market, and wait to procure capacity in the spot market.

Figure 2 describes the truncated phenomenon of the contract capacity; that is, when the capacity price in the spot market is lower than the forwarder's willingness-to-pay, the tiny increase of wholesale price will lead to a sharply change of the contract purchasing quantity, while when the capacity price in the spot market is close to or higher than the forwarder's willingness-to-pay, the change of capacity price in the contract market has less effect on the contract purchasing quantity. This is also consistent with the case in reality.

\subsection{The Carrier's Optimal Pricing Strategy.}

Case $1(\widetilde{p}<r+\lambda)$. In this case, the forwarder's capacity purchasing decision is not affected by his reference price; his contract purchasing quantity is only related to the price $\widetilde{p}$ in the spot market and contract price $k$ in the current period. The parameters in this case satisfy the following condition: $q^{*}=\mu_{\mathrm{Q}}+z_{q} \sigma_{\mathrm{Q}}, z_{q}=\Phi^{-1}[1-k / \tilde{p}], \tilde{p}<r+\lambda$, and $\beta \leq k \leq r+\lambda$. And the carrier's expected profit is a concave

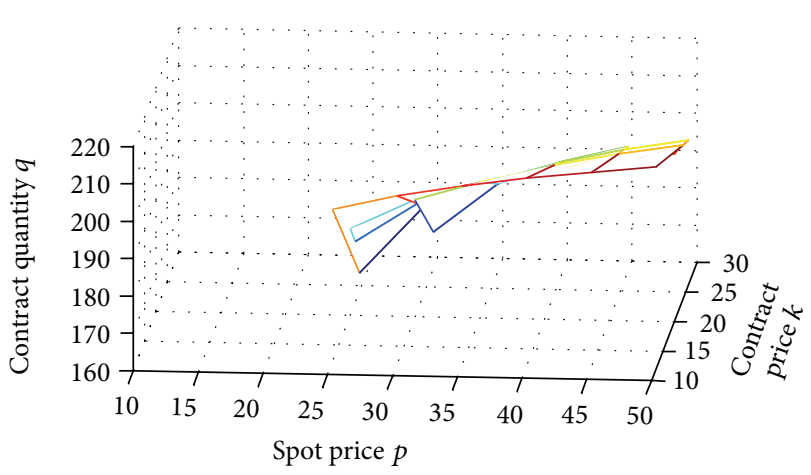

FIGURE 2: The relationship among the contract purchasing quantity, spot price, and contract price (observation chart in azimuth $10^{\circ}$ and angle $25^{\circ}$ ).

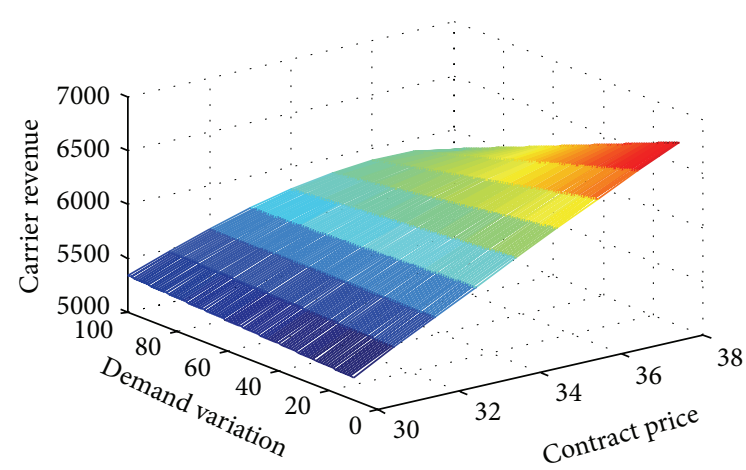

FIGURE 3: The relationship among the carrier's profit, contract price, and the demand variance in the spot market.

function of contract price $k$; the carrier's optimal contract price is a result of Theorem 5 (Figure 3).

As an intermediate agent, the forwarder's capacity demand is driven by the downstream shipper's freight transport demand. Generally, the forwarder gains the price difference by providing additional freight service, that is, the cost-plus pricing policy used in this paper. According to the analysis in Section 3.2.1, we cannot obtain the optimal contract wholesale price of the carrier, and it is difficult to analyze the nature of the carrier's profit function. In view of this problem, we employ a simulation analysis to investigate the carrier's profit function, and we draw the following conclusion: when the capacity demand of the downstream shippers satisfies $\mu_{\mathrm{Q}}>3 \sigma_{\mathrm{Q}}$, the carrier profit function is monotonically increasing with respect to the contract wholesale price $k$; otherwise when $\mu_{\mathrm{Q}} \leq 3 \sigma_{\mathrm{Q}}$, it is a concave function of the contract wholesale price.

If the carrier knows about the forwarder's capacity demand and the demand volatility is small, the forwarder will make the contract wholesale price equal to the capacity price in the spot market price to maximize his expected profit, so the forwarder does not procure capacity in the contract market. In the spot market, the forwarder will procure capacity equal to the capacity demand of the downstream 
shippers (we assume that the forwarder must provide enough capacity for the current capacity demand of the downstream shippers), in this case, the carrier must make the contract wholesale price equal to the capacity price in the spot market. Secondly, the carrier knows about the forwarder's capacity demand, but the demand volatility is very large, the carrier faces the risk of capacity overage, the contract wholesale price is not equal to the capacity price in the spot market, and the optimal contract wholesale price is less than the capacity price in the spot market, so the forwarder will procure capacity in the contract market. At the same time, the carrier can sell the remainder capacity to other forwarders or shippers in the spot market.

According to the assumption on the capacity demand of the downstream shippers, this capacity demand satisfies $\mu_{\mathrm{Q}}>3 \sigma_{\mathrm{Q}}$, so the problem discussed in this paper is the first case, and the carrier's optimal contract wholesale price is $k^{*}=\widetilde{p}$. Intuitively, the wholesale pricing strategy equal to the capacity price in the spot market is inconsistent with the real operation. In practice, because a large capacity procurement, the forwarder can get a discount, which is similar to the result of Xiangzhi et al. [27]. By the result of Theorem 2 results, the forwarder's contract procurement is zero. On the contrary, due to the influence of the forwarders reference price and willingness-to-pay in this paper, when $\widetilde{p}<r+\lambda$, the carrier's contract price can achieve the higher bound of the capacity price in the spot market. As a result, in consideration of the long-term relationship, the forwarder still chooses to procure capacity in the contract market.

Case $2(\tilde{p} \geq r+\lambda)$. When $\widetilde{p} \geq r+\lambda$, the forwarder's decisionmaking problem is a classical newsboy model; the forwarder does not consider the spot market when purchasing capacity; this case is similar to the multiple-period problems of Xiangzhi et al. [27]; the difference is that Xiangzhi et al. [27] do not consider the case that the carrier can sell the remainder capacity in the spot market.

Figure 4 shows that when the demand variance of the downstream shippers is bigger $\left(\mu_{\mathrm{Q}}<3 \sigma_{\mathrm{Q}}\right)$, the carrier's profit function is monotonically increasing with respect to the contract price; otherwise when $\mu_{\mathrm{Q}}>3 \sigma_{\mathrm{Q}}$, the carrier's profit function is a concave function of the contract price. This is similar to the results of Section 3.2.1. According to the assumption of the capacity demand of the downstream shippers, the capacity demand satisfies $\mu_{\mathrm{Q}}>3 \sigma_{\mathrm{Q}}$. So the carrier's optimal contract wholesale price is $k_{t}^{*}=r_{t}+\lambda$.

The contract wholesale price of the carriers is the forwarder's willingness-to-pay. According to the results of Section 3.1, the forwarders does not procure capacity in the contract market, because the carrier earns all consumer surplus of the forwarder through the contract wholesale price. If the forwarder does not choose to procure capacity in the contract market, his capacity cost is the capacity price $\widetilde{p} \geq r+$ $\lambda$ in the spot market. Therefore, the carrier's multiple-period pricing problem is simplified into single-period problem; the forwarder's reference price is $r=r_{0}+(1-\alpha) \lambda$. Intuitively, this pricing strategy equal to the willingness-to-pay is not realistic, and the carrier's profit function is a concave function

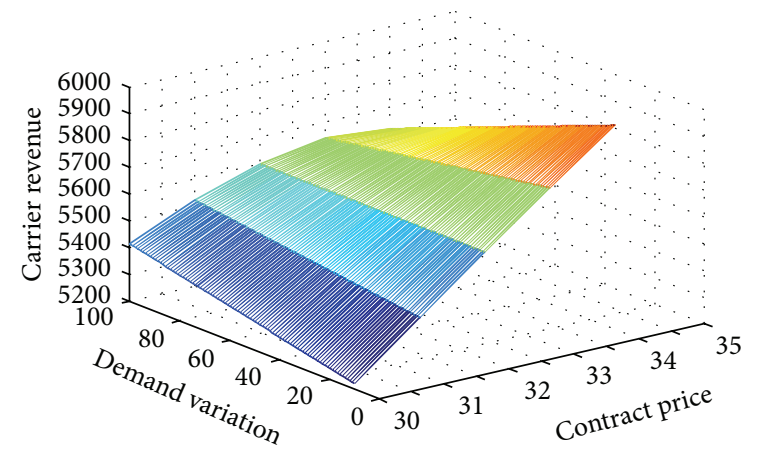

FIGURE 4: The relationship among the carrier's profit, contract price, and the demand variance in the spot market.

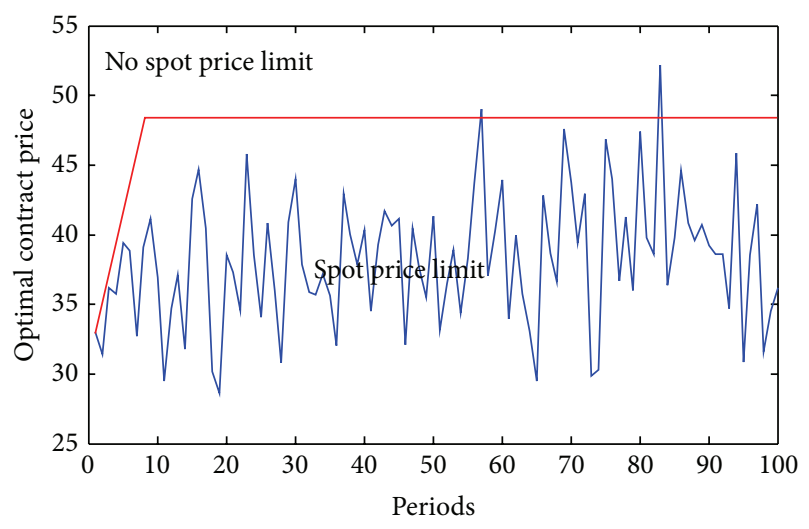

FIGURE 5: Simulation results of the optimal contract price.

of contract wholesale price; that is, there exists an optimal wholesale price less than the willingness-to-pay. By the result of Theorem 2, the forwarder's capacity procurement should be equal to zero. But the relationship among the forwarder's reference effect, capacity in the spot market, and the willingness-to-pay enables the carrier to charge a highest contract wholesale price equal to the forwarder's willingnessto-pay.

Case 3 (mixed decision analysis). According to analysis of Section 3.2.1, the carrier optimal contract wholesale price is $k^{*} \rightarrow \min \{r+\lambda, \widetilde{p}\}$.

In this section, we set $r_{1}=25$ (which satisfies $\widetilde{p}_{1} \geq$ $\left.r_{1}+\lambda\right)$ and use the matlab software to analyze the impact of the capacity price in the spot market randomly generated on the carrier's decisions, and the capacity price in the spot market follows the normal distribution $\widetilde{p}_{t} \sim N(40,10)$. The simulation results are as shown in Figure 5.

In the period $t=1$, when the condition $\widetilde{p}_{1} \geq r_{1}+\lambda$ holds, when there is no capacity price in the spot market influenced, the carrier's optimal contract wholesale price is $k=r+\lambda$; here we assume that the forwarder has a psychological limit value $\bar{k}$ when purchasing capacity, so the carrier's optimal contract wholesale price must satisfy $k \leq \bar{k}$. When the capacity price in 
the spot market satisfies $\widetilde{p}_{1} \sim N(40,10)$, the simulation shows that the carrier's optimal contract wholesale price fluctuates with the forwarder's willingness-to-pay $r_{1}+\lambda$ in the period $t=1$ as the mean. And in some periods, with the influence of the capacity price in the spot market, the carrier's contract wholesale price is beyond the forwarder's psychological limit value.

\section{Conclusions and Future Research}

The contract between the carrier and forwarder is a longterm issue, and the repeated contract business makes the forwarder develop a reference point on the contract price, and this reference effect, to a large extent, affects the forwarder's contract purchasing decisions. Based on that, this paper introduces the reference effect into the sea-cargo supply chain and studies a multiple-period contract problem between the carrier and forwarder. It is found that when the capacity price in the spot market is less than the forwarder's willingnessto-pay, the forwarder's contract purchasing decision is not affected by the reference effect, only by the capacity price in the spot market, and the multiple-period contract problem can be simplified into a single-period game. In addition, the carrier's optimal contract wholesale price approaches the capacity price in the spot market. Although, it is difficult to derive the closed-form solution, we employ the numerical simulation to study the carrier's contract pricing policy in two cases.

The paper only studies the contract business between the carrier and forwarder in the sea-cargo supply chain when the spot market and contract market coexist. However, we do not consider the information asymmetric and the specific mode of reference effect, for example, when the reference effect is asymmetric information between the carrier and forwarder, what happens on her contract pricing policy. Moreover, there are other reference effect modes in economics and psycology; it would be interesting to examine which reference effect mode is more realistic.

\section{Acknowledgments}

The author thanks the editor, associate editor, and two anonymous reviewers for their constructive suggestions, which have improved this paper tremendously. This work was partially supported by the National Natural Science Foundation of China under grant Nos. 71172175, 71002070, and 71002106, which are gratefully acknowledged by the authors.

\section{References}

[1] S. Spinler, Capacity Reservation for Capital-Intensive Technology: A Options Approach, vol. 525, Springer, Heidelberg, Germany, 2003.

[2] R. Hellermann, Capacity Options for Revenue Management. Theory and Applications in the Air Cargo Industry, vol. 575, Springer, Heidelberg, Germany, 2006.

[3] D. Sigworth, "Contracting: making the rate case," Traffic World, vol. 268, no. 17, pp. 32-33, 2004.
[4] D. Gupta, Carrier-Forwarder Contracts in the Air Cargo Industry, Working Paper, 2006.

[5] R. G. Kasilingam, "Air cargo revenue management: characteristics and complexities," European Journal of Operational Research, vol. 96, no. 1, pp. 36-44, 1997.

[6] J. S. Billings, A. G. Diener, and B. B. Yuen, "Cargo revenue optimization," Journal of Revenue and Pricing Management, no. 2, pp. 69-79, 2003.

[7] I. Popescu and Y. Wu, "Dynamic pricing strategies with reference effects," Operations Research, vol. 55, no. 3, pp. 413-429, 2007.

[8] D. Kahneman and A. Tversky, "Prospect theory: an analysis of decision under risk," Econometrica, vol. 47, no. 2, pp. 263-291, 1979.

[9] M. A. Lariviere and E. L. Porteus, "Selling to the newsvendor: an analysis of price-only contracts," Manufacturing and Service Operations Management, vol. 3, no. 4, pp. 293-305, 2001.

[10] B. Holmström and P. Milgrom, "Aggregation and linearity in the provision of intertemporal incentives," Econometrica, vol. 55, no. 2, pp. 303-328, 1987.

[11] J. S. Raju and V. Srinivasan, "Quota-based compensation plans for multiterritory heterogeneous salesforces," Management Science, vol. 42, no. 10, pp. 1454-1462, 1996.

[12] H. Varian, Microeconomic Analysis, Norton, New York, NY, USA, 1992.

[13] L. R. Weatherford and S. E. Bodily, "A taxonomy and research overview of perishable-asset revenue management: yield management, overbooking and pricing," Operations Research, vol. 40, no. 5, pp. 831-844, 1992.

[14] D. K. Tscheulin and J. Lindenmeier, "Yield-management-Ein State-of-the-art," Zeitschrift für Betriebswirtschaft, vol. 73, no. 6, pp. 629-662, 2003.

[15] E. S. Mills, "Uncertainty and price theory," Quarterly Journal of Economics, vol. 73, no. 1, pp. 116-130, 1959.

[16] A. H. L. Lau and H. S. Lau, "Newsboy problem with pricedependent demand distribution," IIE Transactions, vol. 20, no. 2, pp. 168-175, 1988.

[17] E. L. Porteus, "Stochastic inventory models," in Handbooks in Operations Research and Management Science, Volume 2: Stochastic Models, D. P. Heyman and M. J. Sobel, Eds., vol. 2, chapter 12, pp. 605-652, North-Holland, Amsterdam, The Netherlands, 1990.

[18] H. S. Lau, "Simple formulas for the expected costs in the newsboy problem: an educational note," European Journal of Operational Research, vol. 100, no. 3, pp. 557-561, 1997.

[19] A. A. Tsay, "The quantity flexibility contract and suppliercustomer incentives," Management Science, vol. 45, no. 10, pp. 1339-1358, 1999.

[20] W. M. Swan, "Airline demand distributions: passenger revenue management and spill," Transportation Research E, vol. 38, no. 3-4, pp. 253-263, 2002.

[21] M. Nerlove, "Adaptive expectations and cobweb phenomena," Quarterly Journal of Economics, vol. 72, no. 2, pp. 227-240, 1958.

[22] R. S. Winer, "A reference price model of brand choice for frequently purchased products," Journal of Consumer Research, vol. 13, no. 2, pp. 250-256, 1986.

[23] G. Sorger, "Reference price formation and optimal marketing strategies," in Optimal Control Theory and Economic Analysis, vol. 3, pp. 97-120, North-Holland, Amsterdam, The Netherlands, 1988. 
[24] E. A. Greenleaf, "The impact of reference price effects on the profitability of price promotions," Marketing Science, vol. 14, no. 1, pp. 82-104, 1995.

[25] D. J. Wu, P. R. Kleindorfer, and J. E. Zhang, "Optimal bidding and contracting strategies for capital-intensive goods," European Journal of Operational Research, vol. 137, no. 3, pp. 657-676, 2002.

[26] J. J. Spengler, "Vertical integration and antitrust policy," Journal of Political Economy, vol. 53, pp. 347-352, 1950.

[27] X. Bu, L. Xu, and L. Su, "Intertemporal pricing and allotment of sea-cargo capacity under reference effect," Journal of Service Science and Management, vol. 1, no. 3, pp. 206-214, 2008. 


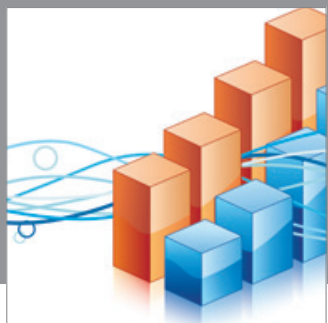

Advances in

Operations Research

mansans

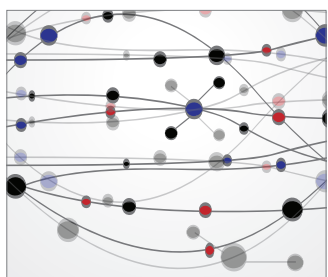

The Scientific World Journal
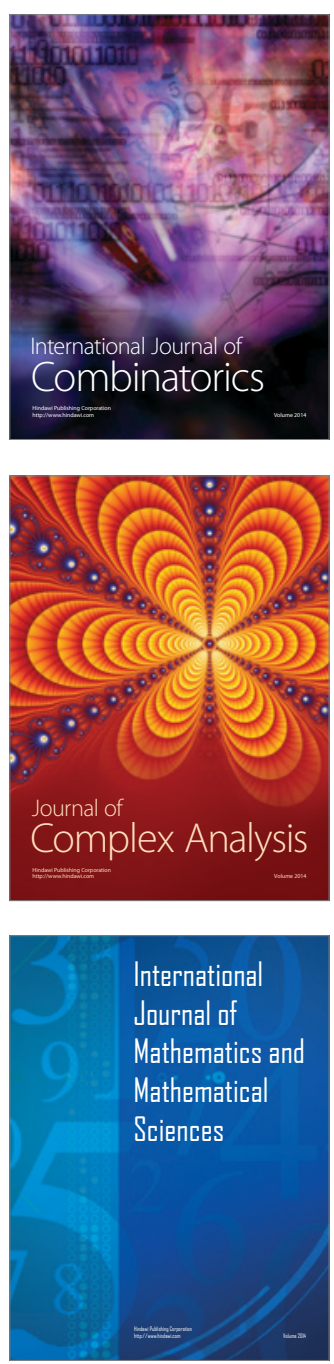
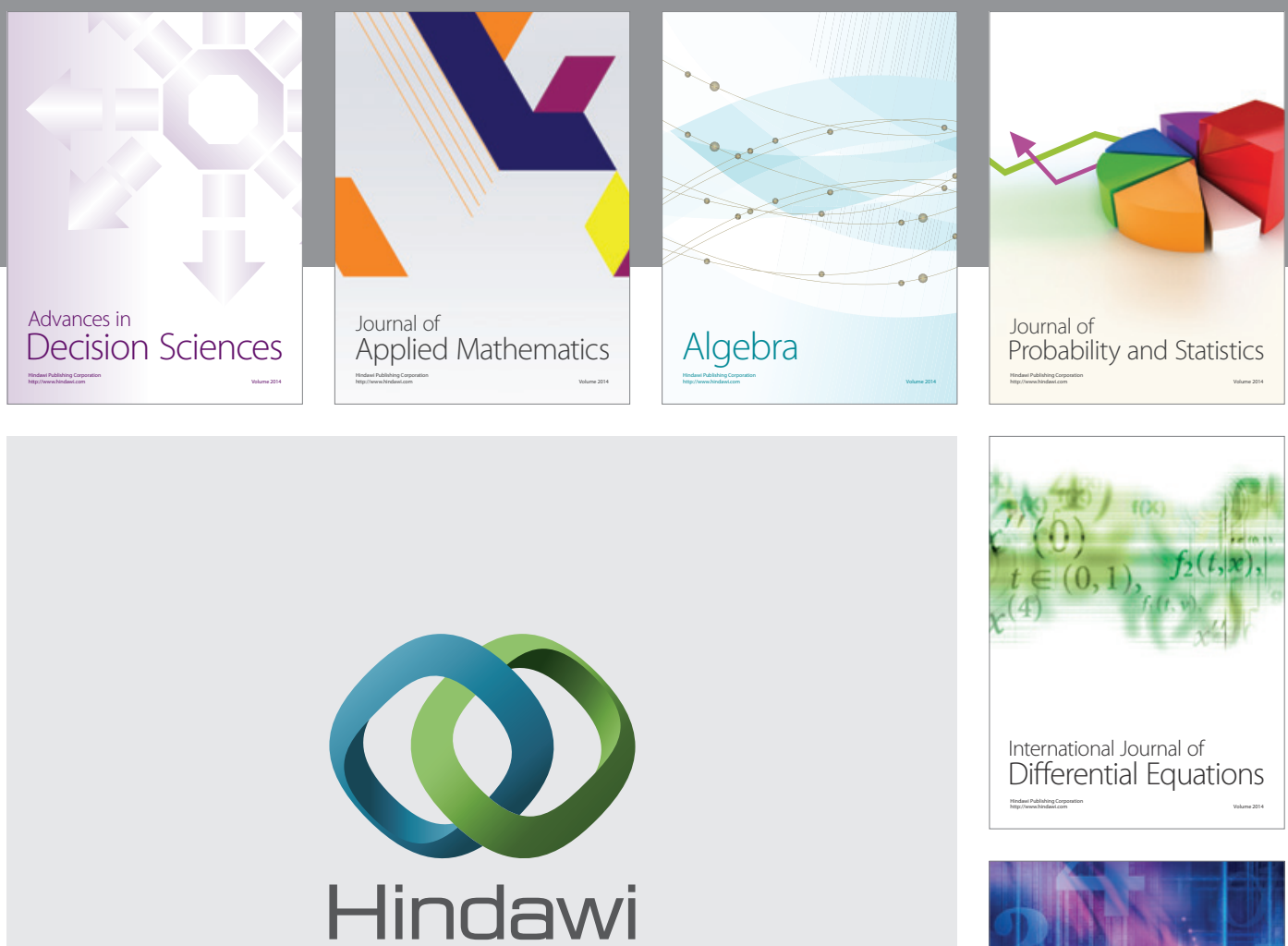

Submit your manuscripts at http://www.hindawi.com
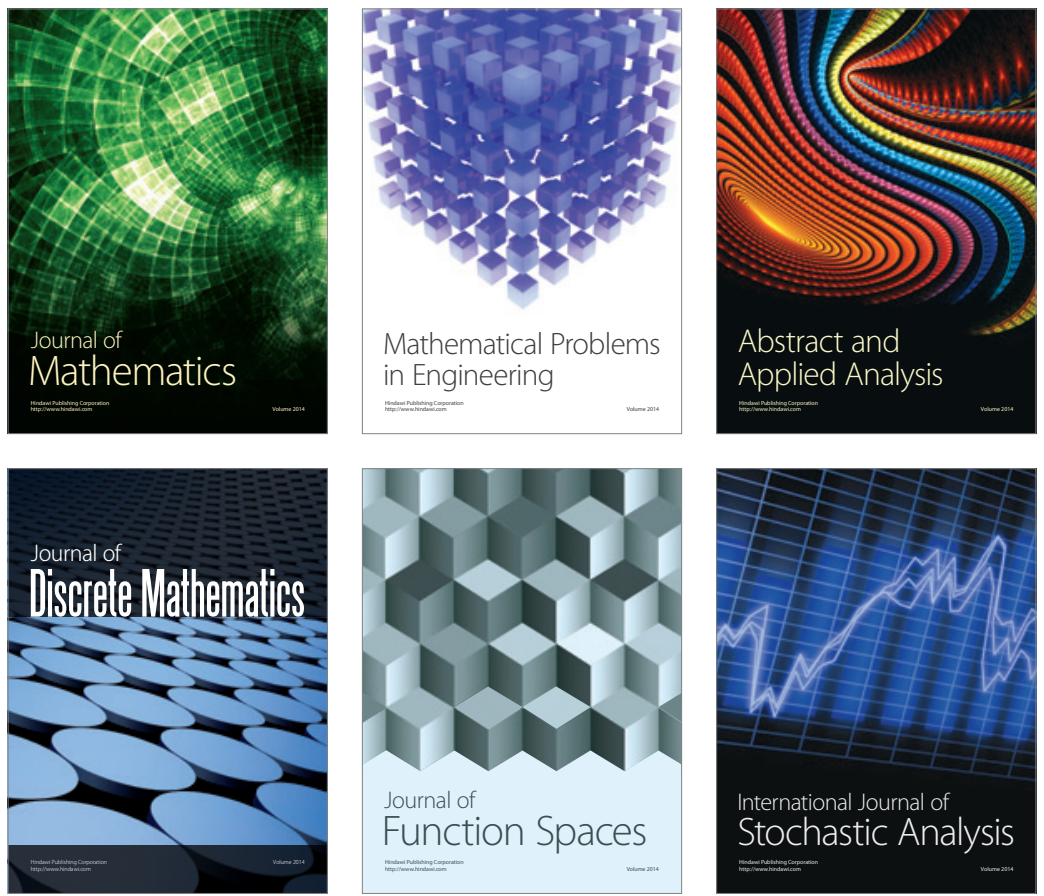

Journal of

Function Spaces

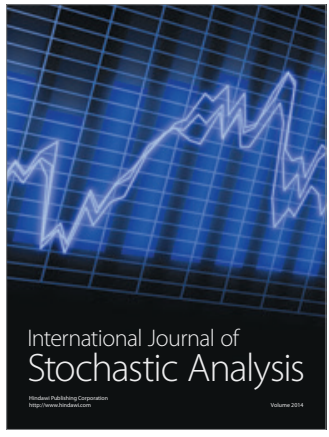

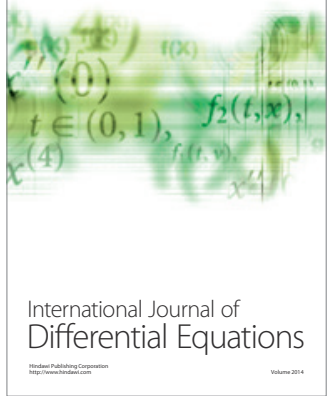
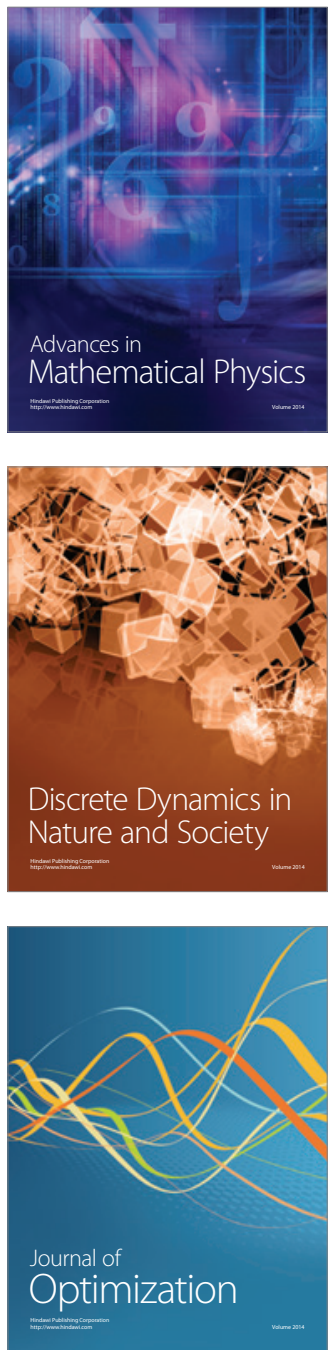